\title{
Политическое положение польского, украинского и русинского народов в конце XIX - начале XX вв.
}

\author{
Иванов Г.Н. \\ Московский государственный институт международных отношений (университет) \\ Министерства иностранных дел Российской Федерации, \\ Россия, 119454, г. Москва, проспект Вернадского, 76 \\ E-mail: gleb-ivanov2001@yandex.ru
}

\begin{abstract}
Аннотация. Статья призвана выявить факторы, которые сыграли ключевую роль в этнополитическом развитии польского, украинского и русинского народов в конце XIX - начале $\mathrm{XX}$ вв. Проводится сравнительный анализ политического положения народов в составе Российской и Австро-Венгерской империй, а также влияния, которое на них оказывали другие этносы. Автор также стремится определить, на каком этапе формирования национальной идентичности находился каждый из народов в начале избранного периода, проследить его этнополитическое развитие и сравнить с тем, каким он предстает перед началом Первой мировой войны. Предполагается, что именно политические факторы, такие как национальная политика империй и политический статус трех указанных народов, оказали наибольшее влияние на их этнополитическое развитие.
\end{abstract}

Ключевые слова: Российская империя, Австро-Венгрия, этнополитика, национальная идентичность, Галиция, Украина.

Для цитирования: Иванов Г.Н. 2021. Политическое положение польского, украинского и русинского народов в конце XIX - начале XX вв. Via in tempore. История. Политология, 48 (2): 338-348. DOI: 10.52575/2687-0967-2021-48-2-338-348.

\section{Political status of the Polish, Ukranian and Rusin people in the end of the XIX - beginning of the XX centuries}

\author{
Gleb N. Ivanov \\ Moscow State Institute of International \\ Relations (University) of the Ministry of Foreign Affairs of the Russian Federation, \\ 76 Vernadsky avenue, Moscow, 119454, Russia \\ E-mail: gleb-ivanov2001@yandex.ru
}

\begin{abstract}
The article is intended to determine what factors played a crucial role in the ethnopolitical development of the Polish, Ukrainian and Rusyn people in the end of the XIX - beginning of the XX centuries. A comparative analysis of the political conditions of the peoples in Russia and AustroHungary as well of the other ethnic groups influence on them is conducted. The author also seeks to identify what stage of formation of national identity each of the peoples reached at the beginning of the period, to trace their ethnopolitical development and compare it with how they appear before the beginning of World War I. It is assumed that political factors, such as the nationalities policy of the empires and the political status of the three peoples mentioned above, had the greatest impact on their ethnopolitical development. The approaches of the two states to the conduct of national policy were seriously different. The greatest significance of all crown lands for this study is Galicia, since most of the peoples we are considering live on its territory.
\end{abstract}

Keywords: Russian Empire, Austro-Hungary, ethnopolitics, national identity, Galicia, Ukraine. 
For citation: Ivanov G.N. 2021. Political status of the Polish, Ukranian and Rusin people in the end of the XIX - beginning of the XX centuries. Via in tempore. History and political science, 48 (2): 338-348 (in Russian). DOI: 10.52575/2687-0967-2021-48-2-338-348.

\section{Введение}

Вопросы этнополитического развития народов в многонациональных империях всегда оставались в поле зрения отечественных и зарубежных исследователей. Именно в конце XIX - начале XX века восточнославянские народы переживают значительные потрясения, которые впоследствии скажутся на формировании их национальной самоидентичности. Цель данной статьи - определить, какие факторы в большей степени повлияли на этнополитическое развитие польского, украинского и русинского народов в данный период времени. В процессе исследования использованы методы сравнительного анализа, синтеза и индукции. Помимо отечественной и зарубежной литературы, автор также использует исторические источники, такие как Первая всеобщая перепись населения Российской империи и перепись населения в Австро-Венгрии 1910 г. Стоит отметить, что, несмотря на чрезвычайно обширную историографию по теме работы, авторы еще не сравнивали политическое положение указанных трех народов в составе Российской и АвстроВенгерской империй. Тем не менее если останавливаться на ключевых трудах по изучению русинского, польского и украинского народа на рубеже XIX и XX века, то стоит отметить книгу М.Э. Клоповой «Русины, русские, украинцы. Национальные движения восточнославянского населения Галиции в XIX - начале XX века» и работы А.И. Миллера, в частности «Украинский вопрос в Российской империи». В своей книге М.Э. Клопова подробно описывает и анализирует историю национальных движений в Галиции, уделяя особое внимание противостоянию русофилов и украинофилов и используя широкий спектр отечественных и зарубежных источников. А.И. Миллер как один из ведущих отечественных специалистов по вопросу национальной политики в Российской империи уделяет особое внимание вопросам украинофильства на территории Малороссии и процессам борьбы с ним со стороны российских властей. Примечательно, что отечественная историография вопроса была изучена и приведена М.Э. Клоповой в статье «Национальные движения восточнославянского населения Галиции XIX-XX вв. в современной русской и украинской историографии» [Клопова, 2015].

\section{Положение народов в Австро-Венгерской империи}

Неоднократные споры и дискуссии как на страницах газет, так и в стенах государственных органов Австро-Венгрии и Российской империи во многом подтверждают, что подходы обоих государств к проведению национальной политики на рубеже столетий серьезно различались. Чаще всего полемика затрагивала именно подходы империй к решению «польского вопроса», поскольку он представлялся наиболее проблемным для обоих государств [Дворецкий, Тимиряев, 2019].

Двуединая империя выстроила сложную систему государственного управления, основанную на привилегированном статусе двух народов: немцев (Цислейтания) и венгров (Транслейтания). Каждая из частей империи осуществляла в большинстве собственную внутреннюю и, соответственно, этническую политику. В качестве примера подобной политической автономии можно привести вопрос о введении всеобщего избирательного права. Если в Цислейтании в 1907 г. оно уже было введено, то Транслейтания лишь через 6 лет частично расширила право голоса, и избирателями стала лишь 1/10 населения земель короны святого Иштвана [Медоваров, 2015]. Особую роль играли и земельные сеймы, законодательные органы коронных земель (провинций) Австро-Венгрии.

Наибольшую значимость из всех коронных земель для данного исследования представляет именно Галиция, поскольку на ее территории проживала большая часть рассмат- 
риваемых нами народов. В 1867 г. австрийские власти предоставили ей ряд прав и привилегий, которые в первую очередь касались польского населения. Подобная мера должна была обеспечить лояльность Вене влиятельной польской знати. Делопроизводство стало вестись на польском языке, получили распространение польские школы, а двумя годами позже польский стал официальным языком коронной земли. Впоследствии поляки не раз занимали ведущие должности при дворе австрийского императора. В частности, министр иностранных дел Российской империи С.Д. Сазонов отмечал, что «сохранение немецкого и венгерского преобладания в монархии Габсбургов было бы невозможно без поддержки поляков» [Булахтин, 2011]. Основой политики польских консерваторов, которые неизменно доминировали в галицийском сейме вплоть до выборов 1907 г., стали принципы полонизации и сохранение польского землевладения. Таким образом, Цислейтания предоставляла властям Галиции свободу действий, изредка вмешиваясь в ее внутриполитический курс. Столь благоприятные политические условия для польского народа не могли не подготовить почву для польского национального движения, центром которого впоследствии и стала Галиция [Кондратенко, 2007].

Если польская элита рассматривалась австрийскими властями как неизменный фактор стабильности в коронной земле, то это не могло не сказаться на украинском народе, который к тому же составлял большинство населения восточной части Галиции. После революции 1848-1849 гг. наместник провинции Агенор Голуховский начал проводить политику, направленную против национальных требований «руського» населения. Стоит отметить, что в австро-венгерских официальных документах до начала XX века отсутствовало понятие «украинец», и все восточнославянское население империи именовалось «рутенами» (Ruthenen). Сами жители Галиции называли себя «русинами» или «руськими» [Миллер, 1997]. Именно это обозначение будет далее использоваться в статье.

По данным переписи населения Австро-Венгрии, которая проводилась в 1910 г., в Галиции проживало 4 миллиона 672 тысячи поляков и 3 миллиона 208 тысяч русинов [Die Ergebnisse der Volkszählung..., 1912]. При этом известно, что польское население проживало в основном в крупных городах и сельской местности Западной Галиции, в то время как в ее восточной части абсолютное большинство составляли русины [Die Verteilung der Umgangssprachen..., 1910].

Попытки Голуховского перевести русинский язык на латиницу, которые вошли в историю под именем «азбучной войны», не увенчались успехом. Во многом такая политика оправдывалась тем, что именно тогда, с начала 60-х гг. и вплоть до окончания XIX в., русины неизменно ассоциировались с русофильским движением, которое выступало за культурное, а иногда и политическое сближение с русским народом и Российской империей. В частности, известный общественный деятель и член галицийского сейма И. Наумович говорил, что «многолетние усилия дипломатов и поляков сделать из нас особый народ рутенов-униатов оказались тщетными... Русь Галицкая, Угорская, Киевская, Московская... - это одна и та же Русь».

В 1870 г. появилась и первая русофильская политическая организация - «Руськая рада». Все это не могло не настораживать польское население и Вену, которые отреагировали довольно жестко на русофильский подъем. Так, еще в 1867 г., когда известный русофил Я. Гловацкий от имени галицийских русинов собирался принять участие в проходившей в Москве Всероссийской этнографической выставке, в его квартире был проведен обыск, началась травля в прессе, а сам он оказался отстранен от преподавания во Львовском университете и был вынужден покинуть Австро-Венгрию. В 1882 г. в ходе «процесса Ольги Грабарь» были проведены массовые аресты сторонников русофильского движения по обвинению в государственной измене, многие из них подверглись открытым гонениям [Клопова, 2016]. 
Движение украинофилов, которое начало развиваться одновременно с русофилами, в этот период все еще носило маргинальный характер. Несмотря на то, что так же, как и русофильское движение, украинофилы в принципе не обладали единой политической программой, можно выделить основные политические пункты, которые поддерживались их большинством. Это в первую очередь отрицание русофильской идеи о «политическом единстве русской нации», культурное обособление от русского народа и во многом стремление к объединению Украины под австро-венгерской короной. Стоит также отметить религиозный фактор, который являлся водоразделом между движениями: украинофилы выступали против православия (цареславия) как противоречащего их национальному духу и за распространение греко-католичества, в то время как русофилы выступали за сохранение православной веры, которая является важным культурным связующим механизмом с русским народом. История этого движения начинает отсчет с 1885 года, ознаменовавшегося созданием «Народной рады», - первой политической организации, которую можно отнести к украинскому движению. Пятью годами позже была создана Русько-украинская радикальная партия (РУРП), которая на своем учредительном съезде приняла программу, подготовленную Иваном Франко. Однако партия не имела практически никакой электоральной базы: русины к тому моменту в большей степени сопереживали русофилам, а польская власть еще не отошла от идей полонизации. К тому же ее программа соответствовала ее названию, то есть была радикальной, фокусировалась в основном на социально-экономических аспектах жизни селян, тяготела к левому движению. Это во многом отталкивало от нее как русофилов, так и других украинофилов [Топильский, 2016]. Новый наместник Галиции граф Казимир Бадени оказался перед сложным выбором: оказать поддержку украинофилам и изолировать русофилов, или же, опасаясь роста украинского радикализма, следовать неизменной польской консервативной линии [Клопова, 2016].

В 1890 году было заключено «соглашение Бадени - Романчука», которое ознаменовало новую эру в политическом восприятии русинского народа, в результате чего во Львовском университете была открыта кафедра восточнославянской истории, а также ряд других кафедр, в которых преподавание велось на русинском языке, признанном вторым в коронной земле. Однако избирательная реформа и ряд других пунктов, которые были указаны в соглашении, так и не были претворены в жизнь. Недовольство нарушением соглашения привело к сближению позиций русофилов и «народовцев» (политоним, применявшийся к сторонникам «Народной Рады»), которых можно отнести к умеренным украинофилам. Тем не менее на выборах в Рейхсрат 1897 года «руськая» коалиция потерпела поражение и получила лишь 9 мест.

Следующий этап в эволюции политического представительства русинского народа ведет отсчет с обращения 1900 г. Украинской национально-демократической партии (УНДП). Новая партия, которая выделилась из состава РУРП, сформулировала четкую предвыборную программу, в которой наряду с такими понятиями как «руський» и «русин» впервые используется слово «украинско-руський», представляющее собой переходную форму к понятию «украинский» [Клопова, 2016]. Основным политическим пунктом программы было создание отдельной провинции с широкой автономией, куда бы вошли территории Буковины и Галиции с преимущественно русинским населением. В 1900 году в своем обращении партия уже говорит о независимой «Русь-Украине»как политическом идеале, к которому она стремится. УНДП сразу же заняла ведущие позиции в русинском обществе. Новые выборы в Рейхсрат 1907 г. кардинально изменили ситуацию. Национально-демократическая партия получила 27 мандатов от Галиции и 5 от Буковины, в то время как русофилы, которых постепенно начинают называть «москвофилами», всего лишь 5. Подобный расклад сил позволил украинофилам поднимать вопросы не только в региональном галицийском сейме, но и в общеимперском парламенте, где они могли получить поддержку Вены [Клопова, 2016]. 
Столь явный успех «украинцев» вызвал раскол в рядах польских консерваторов, которые четко разделились по региональному принципу. Краковские или западногалицийские консерваторы выступали за сотрудничество с УНДП, чтобы полностью уничтожить русофильское движение, в то время как подольские или восточногалицийские консерваторы, обладавшие собственностью и землей в местах с преимущественно русинским населением, видели основную угрозу как раз в растущем украинском национализме. На предстоящих выборах в сейм наместник А. Потоцкий поддержал подолян, обеспечив русофилам 10 мест, в то время как у УНДП, на самом деле обладавшей более широкой поддержкой, их было всего 12. Сохранились упоминания о прямых указах наместника содействовать избранию пророссийски настроенных русинов [Булахтин, 2007]. Такая политика привела к росту недовольства украинофилов и убийству Потоцкого студентом радикалом М. Сичиньским.

Впоследствии наиболее влиятельным в галицийской политике стал блок краковских консерваторов и польских национал-демократов, которые вернули политику в прежнее русло поддержки «украинофилов». Эта же коалиция и обеспечила подписание нового соглашения в 1914 г., благодаря которому была проведена долгожданная избирательная реформа, результатом которой стало выделение квоты в 61 мандат из 231 для депутатов от русинского народа. К этому моменту украинофилы и УНДП уже считались населением его основными представителями [Клопова, 2016]. Умеренные русофилы или «старорусины», а также «московофилы» оказались вытеснены с политической арены.

Говоря о русинском народе в современном понимании, то есть об отдельном восточнославянском этносе или этнокультурной группе, следует отметить, что никаких отдельных политических прав в Австро-Венгрии у него не было. Как и украинский народ, в официальных документах империи он именовался «рутенами». Поскольку территория расселения современных русинов представляет собой Карпатскую или Угорскую Русь, то мы должны обратить внимание на северо-восточные комитаты (уезды) Королевства Венгрия, ведь эти земли входили тогда именно в эти административно-территориальные единицы.

По данным переписи населения Австро-Венгрии 1910 г., в Транслейтании проживало 472000 чел., которые говорили на русинском языке [Суляк, 2016]. Важно отметить, что в силу удаленности от Львова, который являлся центром политической жизни русинов, события, которые происходили в Галиции, оказывали на русинов Транслейтании минимальное воздействие. Примером отсутствия или чрезвычайно малой коммуникации между карпатскими и галицийскими русинами (впоследствии «украинцами») может стать вытеснение из разговорной речи слова «русин» и замена его словом «украинец». Если в Галиции к началу Первой мировой войны слово русин уже выходит из употребления, то в северо-восточных комитатах Транслейтании оно сохраняется и, как мы видим, не выходит из употребления и по сей день [Веселов, 2016].

Невозможно обойти стороной и отсутствие политических прав и возможностей карпаторусин. Транслейтания являлась более централизованным субъектом империи, нежели Цислейтания. Законодательные собрания комитатов практически не имели никаких полномочий, и вся власть была сосредоточена в руках парламента Транслейтании. Избирательный ценз в венгерской части Австро-Венгрии являлся одним из самых жестких в мире. На последних выборах в 1910 г. численность избирателей составляла лишь 6,4 \% от общего населения страны. Число представителей невенгерского происхождения, которые были избраны на выборах в парламент в 1906 г., составляло 26 чел. из 413 - это наибольший показатель за все время его существования. Единственным официальным языком Транслейтании был венгерский. Предположительно за всю историю существования парламента Транслейтании в него так и не был избран ни один представитель от русинов [András Gerö, 2014, p. 5-7]. 


\section{Политическое положение народов в Российской империи}

В Российской империи, в свою очередь, государственное управление осуществлялось намного проще и имело более централизованный характер. Царство Польское, несмотря на свое название, являлось, по сути, формальным образованием, не имевшем прав в законодательной сфере. Однако в отличие от австрийской Галиции, Царство Польское было моноэтничным. Во всех привислинских губерниях, кроме Сувалкской, поляки составляли абсолютное большинство населения. Значительных групп, которые могли бы каким-либо образом противостоять польскому населению, в восточных губерниях не было [Первая всеобщая перепись... 1905].

K 3-й четверти XIX в. практически вся власть в Царстве была сосредоточена в руках назначаемого императором Варшавского генерал-губернатора, делопроизводство велось повсеместно на русском языке, а Новый Государственный Совет из исполнительного органа власти был преобразован в совещательный.

Закон 1864 г. предписал всем школам, находящимся на территории Царства Польского, вести обучение на русском языке, за исключением преподавания закона Божьего. Начиная с 1883 г. преподавание и делопроизводство в Варшавском университете также было переведено на русский язык. Подобные меры не могли не привести к подъему национального самосознания и радикализации польского национального движения в России. Достаточно сказать, что в период с 1895 по 1900 г. из 59 уличных демонстраций на всей территории Российской империи 25 прошли в Царстве Польском и только 3 - в русских губерниях.

Первой значительной польской партией стала Национально-демократическая партия Польши (ННДП), сформированная в 1897 г. в Варшаве и объявившая себя представителем всего польского народа. Эта партия с самого начала отказалась вести «борьбу против захватчиков» вооруженными методами. Оформившаяся в 1894 году, Польская партия социалистов (ППС) Юзефа Пилсудского все же оставалась маргинальной и слишком радикальной силой для того, чтобы заполучить массовую поддержку. В отличие от ННДП она сочетала националистические лозунги с социалистическими, призывая ликвидировать социальное угнетение и создать независимую Польшу. С ее точки зрения, движущей силой в освобождении польского народа должен был стать пролетариат, за которым бы последовали и другие классы [Кондратенко, 2007].

С подписанием манифеста об усовершенствовании государственного порядка 1905 г. у польских партий появилась возможность доносить свою позицию на государственном уровне. В Государственной думе I созыва сформировалось польское коло численностью в 35 депутатов, из которых 27 принадлежали к ННДП. На одном из первых заседаний лидер этой фракции Я. Гарусевич заявил протест против «посягательств и вообще против попрания прав польского народа». Главным требованием депутатов стало восстановление реальной автономии Царства Польского. Во II созыве польские депутаты получили уже 46 мест и попытались перевести заявления об автономии в законодательную плоскость. 10 апреля 1907 г. был представлен соответствующий законопроект с пояснительной запиской. Тем не менее он так и не был рассмотрен, поскольку Дума в скором времени была распущена [Кисляков, 2011].

Исторически важным моментом, который во многом определил этнополитическое развитие в малороссийских губерниях, стало издание в 1863 г. циркуляра Киевскому, Московскому и Петербургскому комитету, или же «Валуевского циркуляра», названного так по имени министра внутренних дел П.А. Валуева, запретившего издание широкого ряда литературы на малороссийском языке. Главным катализатором этой меры стало январское восстание 1863 г., которое перекинулось и на Юго-Западный край. Документ принимался во время пика польских выступлений, и лишить восставших поддержки у другого народа империи было крайне важно [Таирова-Яковлева, 2013]. Об этом же говорит и А. Миллер, отмечая в своей книге «Украинский вопрос в Российской империи», что столь острую реакцию российского правительства спровоцировало «сочетание боязни украинского сепаратизма как такового с опасностью его использования польским освободительным движением в своих целях» [Миллер, 2013]. Позже под влиянием этих факторов изда- 
ние книг на «малорусском языке» стало неизменно ассоциироваться с украинофильством, которое, в свою очередь, поддерживалось польской элитой. Из этого можно сделать вывод о том, что первостепенной причиной борьбы с украинофильством были не опасения по поводу характера самого движения, а расширение польского влияния.

Стоит отметить, что «Валуевский циркуляр» возымел полностью обратный эффект в Галиции, способствуя изданию литературы на малорусском языке и организации украинофильских журналов в соседней Галиции. В 1876 г. последовал «Эмский указ», который запрещал ввоз на территорию Российской империи книг на малорусском наречии, обучение в начальных школах на малорусском языке и другие ограничительные меры. Именно тогда, в 70-х гг., Львов и Киев стали «перевалочными пунктами» для русофилов и украинофилов. Первые бежали от гонений в Австро-Венгрии, а вторые - из-за ограничительной политики Российской империи. Перевес в этом «обмене» был в пользу украинофилов, ведь деятельность русофилов не была официально запрещена в двуединой империи, что оставляло им возможность продвигать свои интересы, в то время как в малороссийских губерниях украинофильство столкнулось с ограничениями, которые прямо препятствовали его развитию и распространению, вынуждая искать новые возможности для выражения своих политических взглядов [Миллер, 1997].

К началу XX в. противостояние между русофилами и украинофилами, в частности «народовцами», выходит на межгосударственный уровень. Если раньше оно проявлялось лишь в Галиции, то сейчас к полемике подключаются ведущие российские газеты, представляя собой платформы для формирования общественного мнения. Ярким примером может стать ряд публикаций Д.Л. Мордовцева, В. Драгомирецкого и О. Маковея в журналах «Санкт-Петербургские ведомости» и «Новое время» [Клопова, 2016]. Это свидетельствует о том, что постепенно «малороссийский вопрос» входил в российский политический дискурс.

После Манифеста 17 октября 1905 г. «Валуевский циркуляр» и «Эмский указ» фактически утратили свою юридическую силу, и уже в I созыве Государственной думы образовался так называемый «Украинский блок», состоявший в основном из последователей Грушевского и сторонников Украинской национально-демократической партии (УНДП), располагавшейся в Галиции. Изначально число этой фракции насчитывало 40 депутатов, во II созыве - 47. Важным фактом является то, что «Украинский блок» не выступал с сепаратистскими заявлениями. Его основным требованием было создание национальной автономии для всех украинских земель и федерализация Российской империи. Изменение избирательного закона на выборах в III созыв Государственной думы в этот раз не позволило украинским депутатам попасть в парламент. Тем не менее украинцы симпатизировали эсерам, единственной партии, которая заявляла, так же как и «Блок», о необходимости федерализации, и кадетам, выступавшим за расширение прав малороссов в образовании и использовании своего языка. Например, с 1912 г. действовало соглашение о поддержке кадетских депутатов на выборах в Государственную думу IV созыва в обмен на выступление партии в пользу законопроектов о введении малороссийского языка в судопроизводстве, школьном обучении и организации кафедр в университетах [Михутина, 1997].

Политический статус русинов на территории Российской империи практически не отличался от его статуса в Австро-Венгрии. К русинам здесь относили жителей Хотинского уезда Бессарабской губернии, который еще часто называли «Бессарабской Буковиной», и ряда других уездов северо-западного Поднестровья. При описании жителей этих регионов указывается, что «по этнографическому родству бессарабских русинов необходимо причислять и относить не столько к нашим малороссам, сколько к зарубежным». Точнее, этнограф П.А. Несторовский относит их к потомкам «червоноруссов», как и «две других разновидности того племени»: карпатских русин и галичан [Несторовский, 1905]. По его мнению, в их речи слышен гуцульский элемент, который также является подтверждением их родственности с карпаторусинами, так как гуцулы являются родственным русинам этносом, проживающим немного восточнее них. Официально приравненные к этнокультурной группе малороссийского народа, русины обладали значительно ограниченными политическими правами и возможностями. 


\section{Заключение}

Подводя итоги, следует сказать о том, что политическое положение практически каждого из народов Австро-Венгерской и Российской империи кардинально отличается от положения другого народа. В двуединой монархии польский народ фактически играл роль третьей титульной нации, обладая широкой автономией и проводя собственную этническую политику, в то время как в России он сталкивался с притеснениями ввиду того, что именно поляки рассматривались как угрожающий империи элемент. Если в Галиции польская элита и интеллигенция проводила политику полонизации в отношении русинского населения, то в Царстве Польском уже проводилась русификация в отношении самого польского населения. Стоит отметить, что Галиция представляла собой регион с двумя конкурирующими между собой этносами, где конфликт выражался не только в этническом, но и в социальном плане. Это противостояние использовала и Вена, для которой это было инструментом сдерживания и использования польской элиты в своих целях. В Царстве Польском противостояние шло на другом уровне - между Петербургом и польским населением. Активное подавление польских выступлений и отказ от уступок привели к радикализации польского движения.

В отличие от централизованного и единого польского народа со своим национальным самосознанием, украинский народ в Галиции до середины XIX в. воспринимал себя скорее как локальную и социальную группу. Его этнополитическое развитие в конце века было неизменно связано с той политической позицией, которой придерживалось большинство населения. Именно поэтому происходит постепенный отход от употребления слова «русин», которое первоначально просто означало человека «русской веры», и замена его понятием «украинец», обладающего не только этническим, но и политическим значением. Особую роль в формировании украинского этноса сыграло политическое положение, в котором он оказался. Гонения на русофилов и политическая автономия Галиции стали благоприятной почвой для появления первых украинских политических партий, которые смогли добиться успехов не только на локальных выборах, но и на выборах в общеимперский Рейхсрат.

В Российской империи «малороссы» фактически были приравнены по своим правам к «великороссам», поскольку оба народа если и считались разными, то все равно чрезвычайно близкими друг к другу. Доминирующей в середине - конце XIX в. в малороссийских губерниях оставалась некая «малорусская» идентичность, которая не была окончательно сформированной и скорее представляла собой территориально-социальную группу, как и в Галиции. Как уже было упомянуто, для Российской империи основную опасность представляло распространение польского влияния, что и спровоцировало издание «Валуевского циркуляра», а затем и Эмского указа. Эта мера позволила сохранить малороссийские губернии в орбите своего влияния, но одновременно усилила развитие украинского движения в Галиции. С 1905 г. основной силой, представляющей малороссийские земли с национальных позиций, стало «украинское коло», которое опиралось на идеи Грушевского в силу того, что указ и циркуляр утратили свою силу.

Отсутствие политических возможностей в совокупности с влиянием других народов привели к тому, что русинский народ сохранил свою локальную идентичность. Удаленность от центров политической жизни во многом делала как этническую политику, так и попытки воздействия на население неэффективными. Как бессарабские, так и карпатские русины находились на территории, где пересекались сферы влияния различных народов, что также позволило им сохранить свою культурную автономию.

Рассмотрев этнополитическое развитие польского, украинского и русинского народов в указанный период, можно сделать вывод о том, что политическое положение народа во многом являлось определяющим фактором его этнополитического развития в этот период. Эволюция и становление украинского народа является примером эффективного воздействия политических институтов на этнополитическое развитие этноса. Тем не менее 
национальное самосознание и влияние других народов при определённых обстоятельствах могут свести на нет национальную политику государства. Это подтверждается неэффективностью этнической политики в отношении польского населения, народа с уже оформленным самосознанием, и русинского населения, находившегося между другими сильными и влиятельными народами.

\section{Список литературы}

1. Булахтин М.А. 2011. Политическая модернизация и польская элита в Галиции начала XX в.: урок для России? Власть, 9: 150-154.

2. Булахтин М.А. 2007. Русофилы и краковские консерваторы в условиях политической борьбы в Галиции на рубеже XIX-XX веков. Вестник Балтийского федерального университета им. И. Канта. Серия: Гуманитарные и общественные науки, 12: 47-53.

3. Веселов В.И. 2016. Русины Закарпатской области Украины: институализация и функционирование общественных организаций в 1989-2001 гг.: дисс. канд. ист. наук, Москва, 185.

4. Дворецкий Е.В., Тимирязев Д.О. 2019. Полемика Б.Н. Чичерина и Н.К. Ренненкампфа в 1898-1899 гг. по польскому вопросу в политике России, Германии и Австро-Венгрии. Былые годы, 53: 1310-1317.

5. Кисляков А.С. 2011. Национально-политическая программа польского коло в Государственной думе I и II созывов (1906-1907 гг.). Вестник Московского университета. Серия 8. История, 4: 89-99.

6. Копова М.Э. 2015. Национальные движения восточнославянского населения Галиции XIX-XX вв. в современной русской и украинской историографии. Славянский альманах, 1-2: 365-377.

7. Клопова М.Э. 2016. Русины, русские, украинцы. Национальные движения восточнославянского населения Галиции в XIX - начале XX века. М., Индрик, 280.

8. Кондратенко Д.П. 2007. К вопросу о радикальности польского национальноосвободительного движения в последней трети XIX в. Вестник ВятГУ, 19: 43-47.

9. Медоваров М.В. 2015. Кризис Австро-Венгрии и русская консервативная мысль накануне Первой мировой войны. Вестник Нижегородского университета им. Н.И. Лобачевского, 1: 69-77.

10. Миллер А. 1997. Внешний фактор в формировании национальной идентичности галицийских русинов. Migracijske i etničke teme, 13: 7-14.

11. Миллер А. 2013. Украинский вопрос в Российской империи. К., Laurus, 416.

12. Михутина И. 1997. Украинский вопрос и русские политические партии накануне Первой мировой войны. В кн.: Россия - Украина: история взаимоотношений. М., Школа «Языки русской культуры»: 197-208.

13. Несторовский П.А. 1905. Бессарабские русины. Историко-этнографический очерк. Варшава, Типография «Сатурн», 174.

14. Первая всеобщая перепись населения Российской империи под редакцией Н.А. Тройницкого. 1905. Наличное население обоего пола по уездам, с указанием числа лиц, преобладающих родных языков [Вып. 7]. СПб., Изд. Центр. Стат. комитетом М-ва вн. дел, 42.

15. Суляк С.Г. 2016. Русины в воспоминаниях участников Великой войны. Русин, 2 (44): 73-92.

16. Таирова-Яковлева Т.Г. 2013. «Валуевский циркуляр» и запрет использования украинского языка. Вестник СПбГУ. Серия 2. История, 4: 55-60.

17. Топильский А.Г. 2016. Радикальное движение в Галиции первой половины 1890-х гг. Вестник Тамбовского университета. Серия: Гуманитарные науки, 5-6 (157-158): 156-160.

18. András Gerő. 2014. Nationalities and the Hungarian Parliament (1867-1918). Paper presented at the conference «Parliaments and Minorities: Ethnicities, Nations and Religions in Europe, 1848-1948», 12-14 May 2014.

19. Die Ergebnisse der Volkszählung vom 31. Dezember 1910 in den im Reichsrate vertretenen Königreichen und Ländern. 1912. 1. Heft. Die Summarischen Ergebnisse der Volkszählung, Wien.

20. Die Verteilung der Umgangssprachen in den im Reichsrate vertretenen Königreichen und Ländern nach den Ergebnissen der Volkszählung vom 31. Dezember 1910. Available at: https://anno.onb.ac.at/cgi-content/anno-plus?aid=ost\&datum=0001\&page=543\&size=45. 


\section{References}

1. Bulakhtin M.A. 2011. Politicheskaya modernizatsiya i pol'skaya elita v Galitsii nachala XX v.: urok dlya Rossii? [Political modernization and the Polish elite in Galicia at the beginning of the 20th century: a lesson for Russia?]. Vlast', 9: 150-154 (in Russian).

2. Bulakhtin M.A. 2007. Rusofily i krakovskie konservatory v usloviyakh politicheskoy bor'by v Galitsii na rubezhe XIX-XX vekov [Russophiles and Krakow conservatives in the context of political struggle in Galicia at the turn of the 19th and 20th centuries]. Vestnik Baltiyskogo federal'nogo universiteta im. I. Kanta. Seriya: Gumanitarnye i obshchestvennye nauki, 12: 47-53 (in Russian).

3. Veselov V.I. 2016. Rusiny Zakarpatskoy oblasti Ukrainy: institualizatsiya i funktsionirovanie obshchestvennykh organizatsiy v 1989-2001 gg. [Rusyns of the Transcarpathian region of Ukraine: institutionalization and functioning of public organizations in 1989-2001]: dis. kand. ist. nauk, Moskva, 185 (in Russian).

4. Dvoretskiy E.V., Timiryaev D.O. Polemika B.N. Chicherina i N.K. Rennenkampfa v 1898-1899 gg. po pol'skomu voprosu v politike Rossii, Germanii i Avstro-Vengrii [Publicistic Disputes B.N. Chicherin and N.K. Rennenkampf in 1898-1899 on the Polish Question in Politics of Russia, Germany and Austrian-Hungary]. Bylye Gody, 53: 1310-1317 (in Russian).

5. Kislyakov A.S. 2011. Natsional'no-politicheskaya programma pol'skogo kolo v Gosudarstvennoy dume I i II sozyvov (1906-1907 gg.) [National-political program of the Polish Kolo in the State Duma of the 1st and 2nd convocations (1906-1907)]. Vestnik Moskovskogo universiteta. Seriya 8. Istoriya, 4: 89-99 (in Russian).

6. Klopova M.E. 2015. Natsional'nyye dvizheniya vostochnoslavyanskogo naseleniya Galitsii XIX-XX vv. v sovremennoy russkoy i ukrainskoy istoriografii [National movements of the East Slavic population of Galicia in the XIX-XX centuries. in modern Russian and Ukrainian historiography]. Slavyanskiy al'manakh, 1-2: 365-377 (in Russian).

7. Klopova M.E. 2016. Rusiny, russkie, ukraintsy. Natsional'nye dvizheniya vostochnoslavyanskogo naseleniya Galitsii v XIX - nachale XX veka [Rusyns, Russians, Ukrainians. National movements of the East Slavic population of Galicia in the 19th - early 20th centuries]. M., Indrik, 280 (in Russian).

8. Kondratenko D.P. 2007. K voprosu o radikal'nosti pol'skogo nacional'no-osvoboditel'nogo dvizhenija v poslednej treti XIX v. [On the question of the radicalism of the Polish national liberation movement in the last third of the 19th century]. Vestnik VjatGU, 19: 43-47 (in Russian).

9. Medovarov M.V. 2015. Krizis Avstro-Vengrii i russkaya konservativnaya mysl' nakanune Pervoy mirovoy voyny [The Austro-Hungarian Crisis and Russian Conservative Thought on the Eve of the First World War]. Vestnik Nizhegorodskogo universiteta im. N.I. Lobachevskogo, 1: 69-77 (in Russian).

10. Miller A. 1997. Vneshniy faktor v formirovanii natsional'noy identichnosti galitsiyskikh rusinov [External factor in the formation of the national identity of the Galician Rusyns]. Migracijske i etničke teme, 13: 7-14 (in Russian).

11. Miller A. 2013. Ukrainskij vopros v Rossijskoj imperii [The Ukranian Question in the Russian Empire]. K., Laurus, 416 (in Russian).

12. Mikhutina I. 1997. Ukrainskiy vopros i russkie politicheskie partii nakanune Pervoy mirovoy voyny [The Ukrainian question and Russian political parties on the eve of the First World War]. V kn.: Rossiya - Ukraina: istoriya vzaimootnosheniy. M., Shkola «Yazyki russkoy kul'tury»: 197-208 (in Russian).

13. Nestorovskiy P.A. 1905. Bessarabskie rusiny. Istoriko-etnograficheskiy ocherk [Bessarabian Rusyns. Historical and ethnographic sketch]. Varshava, Tipografiya «Saturn», 174 (in Russian).

14. Pervaya vseobshchaya perepis' naseleniya Rossiyskoy imperii pod redaktsiey N.A. Troynitskogo. 1905. Nalichnoe naselenie oboego pola po uezdam s ukazaniem chisla lits, preobladayushchikh rodnykh yazykov [The first general census of the population of the Russian Empire, edited by N.A. Troinitsky. 1905. The actual population of both sexes by counties, indicating the number of persons with predominant native languages]. [Vyp. 7]. SPb., Izd. Tsentr. Stat. komitetom M-va vn. del, 42 (in Russian).

15. Sulyak S.G. 2016. Rusiny v vospominaniyakh uchastnikov Velikoy voyny [Rusyns in the memoirs of participants in the Great War]. Rusin, 2 (44): 73-92 (in Russian). 
16. Tairova-Yakovleva T.G. 2013. «Valuevskiy tsirkulyar» i zapret ispol'zovaniya ukrainskogo yazyka [«Valuevsky circular» and the ban on the use of the Ukrainian language]. Vestnik SPbGU. Seriya 2. Istoriya, 4: 55-60 (in Russian).

17. Topilsky A.G. 2016. Radikal'noe dvizhenie v Galicii pervoj poloviny 1890-h gg. [Radical movement in Galicia in the first half of 1890-s]. Vestnik Tambovskogo universiteta. Seriya: Gumanitarnye nauki, 5-6 (157-158): 156-160 (in Russian).

18. András Gerő. 2014. Nationalities and the Hungarian Parliament (1867-1918). Paper presented at the conference «Parliaments and Minorities: Ethnicities, Nations and Religions in Europe, 1848-1948», 12-14 May 2014.

19. Die Ergebnisse der Volkszählung vom 31. Dezember 1910 in den im Reichsrate vertretenen Königreichen und Ländern. 1912. 1 Heft. Die Summarischen Ergebnisse der Volkszählung, Wien.

20. Die Verteilung der Umgangssprachen in den im Reichsrate vertretenen Königreichen und Ländern nach den Ergebnissen der Volkszählung vom 31. Dezember 1910. Available at: https://anno.onb.ac.at/cgi-content/anno-plus?aid=ost\&datum $=0001 \&$ page $=543 \&$ size $=45$

\section{ИНФОРМАЦИЯ ОБ АВТОРЕ}

Иванов Глеб Никитич, студент Московского государственного института международных отношений (университета) Министерства иностранных дел Российской Федерации, г. Москва, Россия

\section{INFORMATION ABOUT THE AUTHOR}

Gleb N. Ivanov, student of Moscow State Institute of International Relations (University) of the Ministry of Foreign Affairs of the Russian Federation, Moscow, Russia 